\title{
Steroids and/or cytotoxic agents should be used early in the management of patients with IPF - The pro argument
}

\author{
Sat Sharma MD FRCPC
}

$I^{d}$

diopathic interstitial pneumonias comprise a heterogenous group of acute and chronic respiratory conditions. Katzenstein and Myers (1) classified these disorders according to several pathologically distinct categories: usual interstitial pneumonitis (UIP), desquamative interstitial pneumonitis - respiratory bronchiolitis interstitial lung disease, acute interstitial pneumonitis, nonspecific interstitial pneumonitis and cryptogenic organizing pneumonitis or bronchiolitis obliterans organizing pneumonia (1). These disorders present with similar clinical features of shortness of breath, diffuse pulmonary infiltrates on chest radiograph, and histologically, a varying combination of inflammation and fibrosis. However, the natural history and response to therapy differs substantially, as some categories have more favourable prognoses than others (2). Idiopathic pulmonary fibrosis (IPF) or fibrosing alveolitis is the clinical terminology for a specific interstitial pneumonia for which the pathological process is UIP. A disorder of unknown etiology, IPF is the most common and most lethal of all interstitial pneumonias.

\section{PROGNOSIS OF IPF}

IPF is a more common disease than previously thought; the incidence is estimated to be 10.7 cases/100,000 men and 7.4 cases $/ 100,000$ women (3). A population-based study reported the prevalence to be 20.2 and 13.2 cases/100,000 men and women, respectively (3). The diagnosis of IPF carries a grave prognosis. From the time of diagnosis, the mean length of survival is documented to be between 3.2 and five years $(2,4)$. A recent cohort study found a median length of survival of 2.9 years for incident cases and nine years for prevalent cases (5).

Although IPF is an inexorably progressive disease, three separate phases have been identified (6). An initial stable phase consists of stable lung functions and no or minimal symptoms. During the symptomatic phase, the patient becomes increasingly dyspneic and desaturates on exercise, and lung functions worsen to a level of between $50 \%$ and $80 \%$. The final stage of rapid decline is characterized by dyspnea and hypoxemia at rest, lowering of vital capacity to less than $50 \%$, respiratory failure and progression to death.

\section{PATHOGENESIS OF IPF}

Pathogenesis of IPF appears to be instigated by four different cells, as well as numerous proteins and mediators. The neutrophils and alveolar macrophages secrete various cytokines, including interleukin-8, tumor necrosis factor-alpha and oxygen free radicals (7). The $\mathrm{T}$ lymphocyte, a major immunoregulatory cell, plays an important role in the initiation and perpetuation of pulmonary fibrosis (8). A Th-1 immune response is mediated by the cytokine interferon-gamma; this mediator is generally prevalent in high levels in granulomatous disorders such as sarcoidosis. The inflammatory response in IPF has been associated with an unregulated Th-2 immune response. The Th-2 cytokines interleukin-4 and interleukin-13 modulate tissue injury and lead to the development and progression of pulmonary fibrosis (9). Finally, fibroblast activation via cytokine interleukin- 8 and others, accompanied by expression of transforming growth factor-beta and connective tissue growth factor, promotes the deposition of extracellular matrix, collagen deposition and fibrosis (10).

\section{TREATMENT OF IPF}

IPF characteristically has a progressive clinical course and a poor prognosis; therefore, it is prudent to consider an early and aggressive approach to therapy. Because IPF is an immune-mediated disease, and inflammation leads to injury and fibrosis, antiinflammatory and immunosuppressive therapy is logical. Recent research has focused on modifying the fibroblast activity with antifibrotic agents, including colchicine, pirfenidone, relaxin and endothelin-1 blockers $(11,12)$. Immunomodulators such as interferon-gamma, a Th-1 cytokine, inhibit transforming growth factor-beta ${ }_{1}$ and, thus, Th-2-induced inflammatory processes $(13,14)$. The antifibrotic and immunomodulator therapies are under investigation and are not presently approved for clinical use. The data for currently available therapy suffer from several limitations: heterogenous patients, disparate study designs, lack of placebo controls, variable doses and durations of treatment, and inadequate outcome assessments. Despite these limitations, the only contemporary rational treatment option for treating this devastating disease process remains corticosteroids (CSs) and/or cytotoxic agents. However, the anti-inflammatory

Sections of Respirology and Critical Care Medicine, University of Manitoba, Winnipeg, Manitoba

Correspondence and reprints: Dr Sat Sharma, BG 034, St Boniface Hospital, 409 Tache Avenue, Winnipeg, Manitoba R2H 2 A6.

Telephone 204-237-2217, fax 204-231-1927, e-mail ssharma@mb.sympatico.ca 
therapy needs to be instituted early. Unfortunately, a clinical nihilism prevails in the medical community pertaining to the pharmacological treatment of IPF. Therefore, most patients already have advanced disease at the time of referral to pulmonary specialists. Most experts advocate early diagnosis and aggressive treatment for appropriate patients with interstitial lung disease secondary to IPF.

\section{CORTICOSTEROIDS}

Despite being the mainstay of therapy for the past several decades, no prospective, randomized, placebo-controlled trial has demonstrated the efficacy of CSs in IPF. Several studies have documented response rates of $10 \%$ to $30 \%$ as defined by quantitative criteria (15-18). Based on subjective assessment, up to $40 \%$ of CS-treated patients acknowledged improvement.

A prospective, nonrandomized study of high dose CS therapy by Flaherty et al (19) showed a higher survival rate in steroid responders. In that study, $27 \%$ of patients with IPF improved, $46 \%$ remained stable and $27 \%$ deteriorated. However, recent retrospective data from the Mayo Clinic demonstrated a lack of benefit from CS therapy (20). Randomized trials comparing CSs with cytotoxic agents or colchicine in patients with IPF have been published. Although initial improvement occurred in patients taking CSs, long term outcomes were unfavourable. Lack of CS efficacy from these trials is difficult to assess because treatment was generally prescribed to the patients with advanced or irreversible stages of IPF. Because of the potential for many serious side effects and limited long term benefit, most experts discourage the use of CSs alone in these patients (21).

\section{CYTOTOXIC AGENTS - AZATHIOPRINE OR CYCLOPHOSPHAMIDE}

Previously, these agents were used in steroid nonresponders, to reduce steroid side effects, and in patients at high risk for morbidity from CSs. Over the past several decades, several clinical trials were conducted in IPF patients with CSs alone or CSs plus azathioprine (AZA) or cyclophosphamide (CP). A favourable response was obtained in $15 \%$ to $50 \%$ of patients treated with immunosuppressives, because multiple mechanisms possibly enhance their therapeutic efficacy.

Winterbauer et al (22) demonstrated an improvement in lung function in IPF patients treated with CSs and AZA compared with CSs alone. A randomized, placebo-controlled trial by Raghu et al (23) showed improved lung function in CS- and AZA-treated patients at one-year intervals. After nine years of follow-up, a survival advantage (mortality rate $43 \%$ versus 77\%) was seen in CS plus AZA-treated patients (23).

$\mathrm{CP}$ has been shown to benefit patients with pulmonary fibrosis secondary to scleroderma. A cohort study of 103 patients showed preservation of lung function and higher survival rates (81\% versus $71 \%$ ) with CP (24). Likewise, several published studies have established the benefits of $\mathrm{CP}$ therapy in patients with IPF. Johnson et al (25) demonstrated improved lung function in seven of 21 patients treated with CP and CSs compared with two of 22 patients treated with CSs alone. An overall survival advantage was evident in CP plus CS-treated patients. In another study by Baughman et al (26), intravenous $\mathrm{CP}$ was associated with improved pulmonary function and a reduction in steroid dose. Dayton et al (27) reported improvement in one and stabilization in seven of 19 patients with IPF taking oral CP. Similarly, Kolb et al (28) showed stabilization of lung function with CP pulse therapy, whereas Zisman et al (29) found limited efficacy with oral CP. More recently, cyclosporine A improved the clinical status of patients with various interstitial pneumonias, including UIP (30).

\section{RECOMMENDATIONS FROM THE AMERICAN THORACIC SOCIETY AND THE EUROPEAN RESPIRATORY SOCIETY (INTERNATIONAL CONSENSUS STATEMENT, JULY 1999)}

After discussing the risks and benefits of therapy, the following treatment may be offered to patients with IPF: CSs $(0.5 \mathrm{mg} / \mathrm{kg}$ initially, tapered over eight weeks to $0.125 \mathrm{mg} / \mathrm{kg}$ ) plus AZA at $2 \mathrm{mg} / \mathrm{kg}$ to $3 \mathrm{mg} / \mathrm{kg}$ (starting at $25 \mathrm{mg}$ to $50 \mathrm{mg}$ and then gradually increasing) or $\mathrm{CP}$ at $2 \mathrm{mg} / \mathrm{kg}$ (beginning at $25 \mathrm{mg}$ to $50 \mathrm{mg}$ and increasing gradually) (21).

\section{CONCLUSIONS}

IPF is a relentlessly progressive disorder with a bleak prognosis. Early aggressive therapy offers the only chance of affecting the staggering mortality in individuals afflicted with IPF. In the future, newer drugs, especially interferon-gamma, relaxin, bosentan and pirfenidone, may prove to be quite beneficial. Lung transplantation may be an option for younger patients.

However, CSs and cytotoxic agents remain the standard therapy for patients with IPF. The international consensus statement echoes this sentiment:

"The exact time that therapy should be started is unknown. The committee believes that response rates may be higher when treatment is initiated early in the course of the disease, before irreversible fibrosis has developed. Failure in some cases appears to reflect delays in initiating treatment. Therefore, the committee recommends that if therapy will be offered to a patient, it should be started at the first indication of clinical or physiological evidence of impairment or documentation of decline in lung function" (21).

\section{REFERENCES}

1. Katzenstein AL, Myers JL. Idiopathic pulmonary fibrosis: Clinical relevance of pathologic classification. Am J Respir Crit Care Med 1998;157:1301-15.

2. Carrington CB, Gaensler EA, Coutu RE, Fitzgerald MX, Gupta RG. Natural history and treated course of usual and desquamative interstitial pneumonia. N Engl J Med 1978;298:801-9.

3. Coultas DB, Zumwalt RE, Black WC, Sobonya RE. The epidemiology of interstitial lung disease. Am J Respir Crit Care Med 1994;150:967-72.

4. Tukiainen P, Taskinen E, Holsti P, Korhola O, Valle M. Prognosis of cryptogenic fibrosing alveolitis. Thorax 1983;38:349-55.

5. Hubbard R, Johnston I, Britton J. Survival in patients with cryptogenic fibrosing alveolitis: A population-based cohort study. Chest 1998;113:396-400.

6. Baughman RP, Lower EE. Therapy for interstitial lung disease. Semin Clin Immunol 1999;17:53-64. 
7. Buttner C, Skupin A, Reimann T, et al. Local production of interleukin-4 during radiation-induced pneumonitis and pulmonary fibrosis in rats: Macrophages as a prominent source of interleukin-4. Am J Respir Cell Mol Biol 1997;17:315-25.

8. Helene M, Lake-Bullock V, Zhu J, Hao H, Cohen DA, Kaplan AM. $\mathrm{T}$ cell independence of bleomycin-induced pulmonary fibrosis. J Leukoc Biol 1999;65:187-95.

9. Furuie H, Yamasaki H, Suga M, Ando M. Altered accessory cell function of alveolar macrophages: A possible mechanism for induction of Th2 secretory profile in idiopathic pulmonary fibrosis. Eur Respir J 1997;10:787-94.

10. Gurujeyalakshmi G, Giri SN. Molecular mechanisms of antifibrotic effect of interferon gamma in bleomycin-mouse model of lung fibrosis: Downregulation of TGF-beta and procollagen I and III gene expression. Exp Lung Res 1995;21:791-808.

11. McAnulty RJ, Laurent GJ. Pathogenesis of lung fibrosis and potential new therapeutic strategies. Exp Nephrol 1995;3:96-107.

12. Ziesche R, Hofbauer E, Wittmann K, Petrov V, Block LH. A preliminary study of long-term treatment with interferon gamma-1b and low-dose prednisolone in patients with idiopathic pulmonary fibrosis. N Engl J Med 1999;341:1264-9.

13. Douglas WW, Ryu JH, Schroeder DR. Idiopathic pulmonary fibrosis: Impact of oxygen and colchicine, prednisone, or no therapy on survival. Am J Respir Crit Care Med 2000;161:1172-8.

14. Raghu G, Johnson WC, Lockhart D, Mageto Y. Treatment of idiopathic pulmonary fibrosis with a new antifibrotic agent, pirfenidone: Results of a prospective, open-label Phase II study. Am J Respir Crit Care Med 1999;159:1061-9.

15. Mapel DW, Samet JM, Coultas DB. Corticosteroids and the treatment of idiopathic pulmonary fibrosis: Past, present, and future. Chest 1996;110:1058-67.

16. Selman M, King TE, Pardo A; American Thoracic Society; European Respiratory Society; American College of Chest Physicians. Idiopathic pulmonary fibrosis: Prevailing and evolving hypotheses about its pathogenesis and implications for therapy. Ann Intern Med 2001;134:136-51.

17. Lynch JP 3rd, White E, Flaherty K. Corticosteroids in idiopathic pulmonary fibrosis. Curr Opin Pulm Med 2001;7:298-308.

18. Nicholson AG, Colby TV, du Bois RM, Hansell DM, Wells AU. The prognostic significance of the histologic pattern of interstitial pneumonia in patients presenting with the clinical entity of cryptogenic fibrosing alveolitis. Am J Respir Crit Care Med 2000;162:2213-7.
19. Flaherty KR, Toews GB, Lynch JP 3rd, et al. Steroids in idiopathic pulmonary fibrosis: A prospective assessment of adverse reactions, response to therapy, and survival. Am J Med 2001;110:278-82.

20. Douglas WW, Ryu JH, Bjoraker JA, et al. Colchicine versus prednisone as treatment of usual interstitial pneumonitis. Mayo Clin Proc 1997;72:201-9.

21. American Thoracic Society. Idiopathic pulmonary fibrosis: Diagnosis and treatment. International consensus statement. American Thoracic Society (ATS) and the European Respiratory Society (ERS). Am J Respir Crit Care Med 2000;161:646-64.

22. Winterbauer RH, Hammar SP, Hallman KO, et al. Diffuse interstitial pneumonitis. Clinicopathologic correlations in 20 patients treated with prednisone/azathioprine. Am J Med 1978;65:661-72.

23. Raghu G, DePaso WJ, Cain K, et al. Azathioprine combined with prednisone in the treatment of idiopathic pulmonary fibrosis: A prospective double blind randomized, placebo controlled clinical trial. Am Rev Respir Dis 1991;144:291-6.

24. White B, Moore WC, Wigley FM, Xiao HQ, Wise RA. Cyclophosphamide is associated with pulmonary function and survival benefit in patients with scleroderma and alveolitis. Ann Intern Med 2000;132:947-54.

25. Johnson MA, Kwan S, Snell NJ, Nunn AJ, Darbyshire JH, Turner-Warwick M. Randomised controlled trial comparing prednisolone alone with cyclophosphamide and low dose prednisolone in combination in cryptogenic fibrosing alveolitis. Thorax 1989;44:280-8.

26. Baughman RP, Lower EE. Use of intermittent, intravenous cyclophosphamide for idiopathic pulmonary fibrosis. Chest 1992;102:1090-4

27. Dayton CS, Schwartz DA, Helmers RA, et al. Outcome of subjects with idiopathic pulmonary fibrosis who fail corticosteroid therapy. Implications for further studies. Chest 1993;103:69-73.

28. Kolb M, Kirschner J, Riedel W, Wirtz H, Schmidt M. Cyclophosphamide pulse therapy in idiopathic pulmonary fibrosis. Eur Respir J 1998;12:1409-14.

29. Zisman DA, Lynch JP 3rd, Toews GB, Kazerooni EA, Flint A, Martinez FJ. Cyclophosphamide in the treatment of idiopathic pulmonary fibrosis: A prospective study in patients who failed to respond to corticosteroids. Chest 2000;117:1619-26.

30. Homma S, Kawabata M, Kishi K, et al. [Cyclosporin A treatment of interstitial pneumonia]. Nihon Kokyuki Gakkai Zassh 2003;41:427-33. 


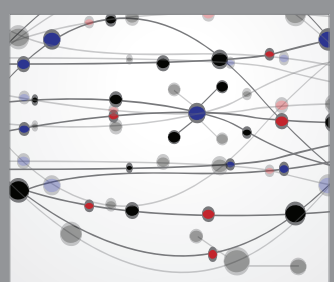

The Scientific World Journal
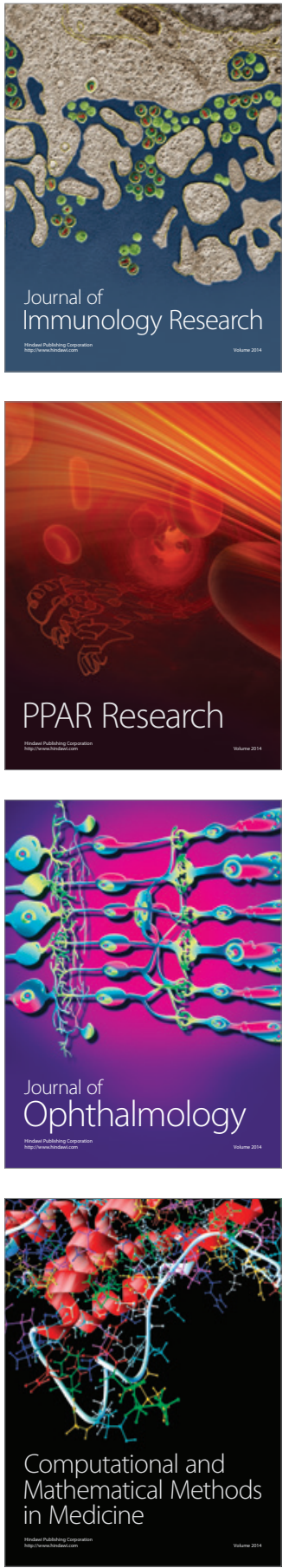

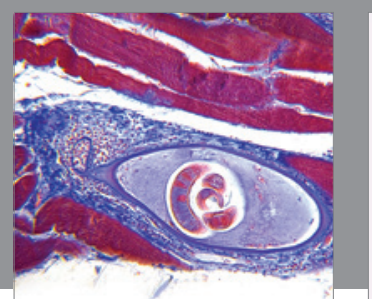

Gastroenterology Research and Practice

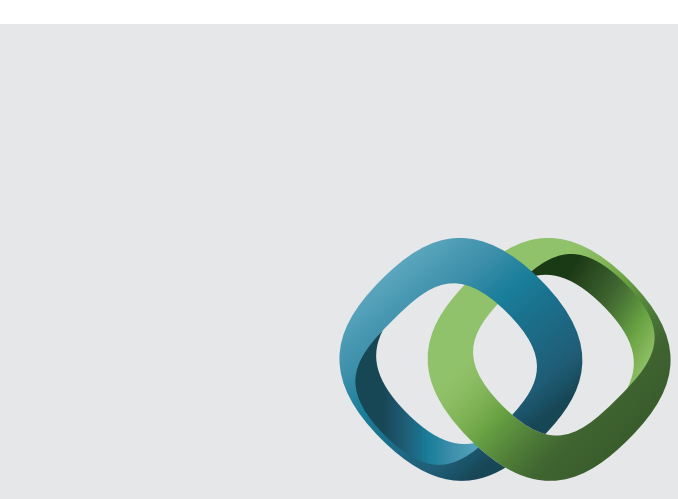

\section{Hindawi}

Submit your manuscripts at

http://www.hindawi.com
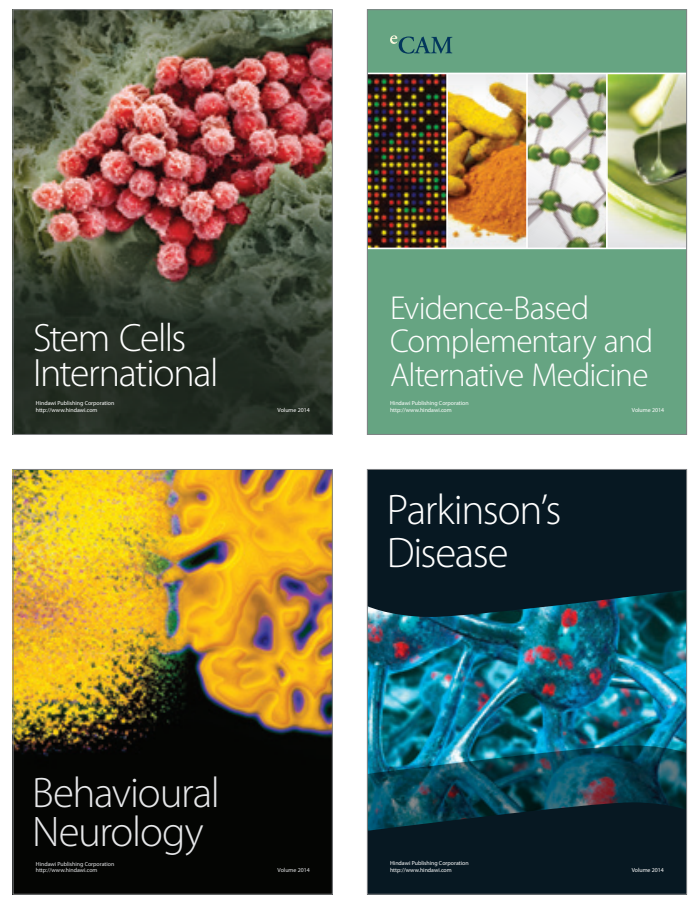
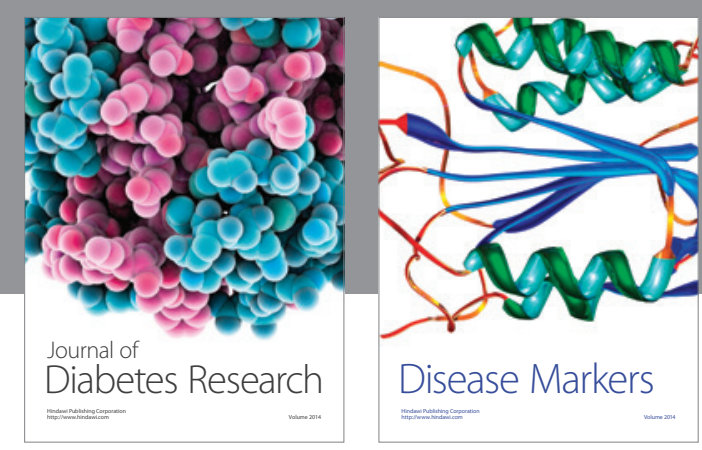

Disease Markers
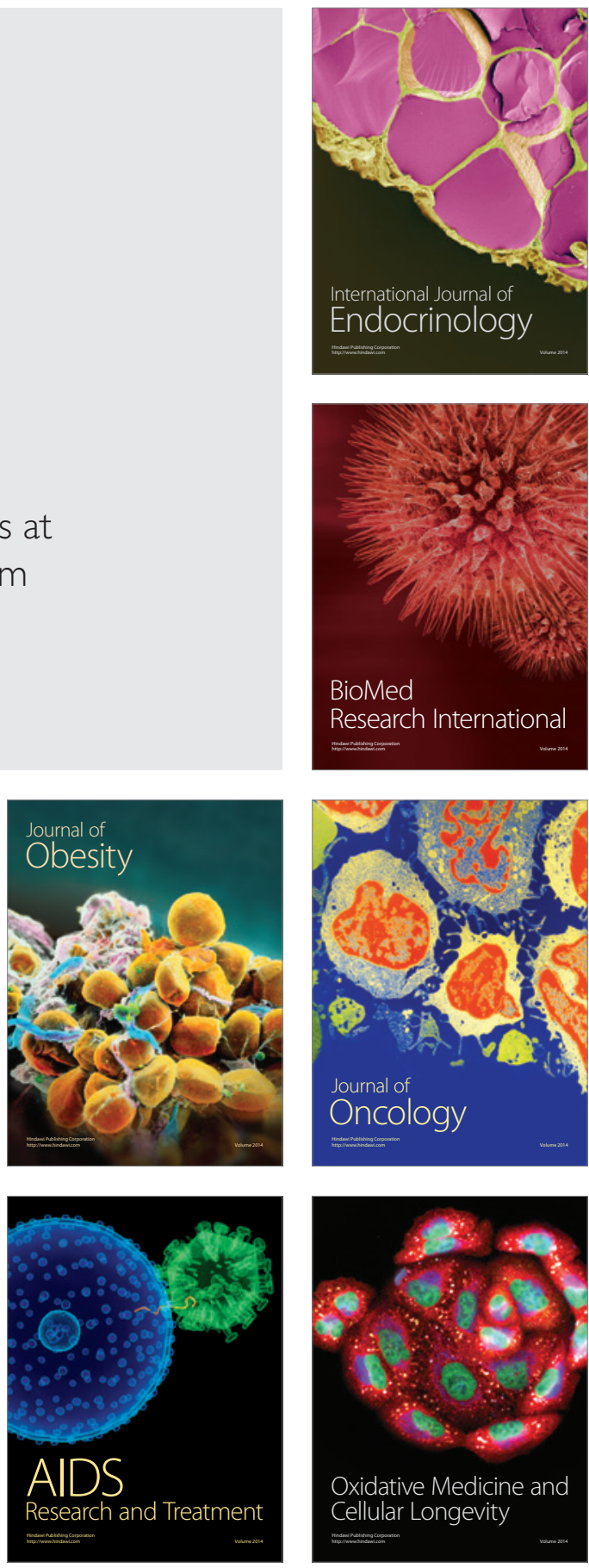